of the eccrine sweat glands in Macaca HuLaTTA. J. Biophys. Biochem. Cytol., 9: 238, 1961. 6) Montagna, W., et al.: Dedifferentiation of sebaceous glands in the mouse after total extirpation with methylcholanthrene. Anat. Rec., $107: 83,1.7$ ) Kingenberg, M., et al. : Biological oxdations. Ann. Rev. Biochem., $29: 669,1960 . \quad$ 8) Kaufman, S. : The enzymatic conversion of phenylalanine to tyrosine. J. Biol. Chem., $226: 511,1957$. 9) Grimm, F.C., et al.: Properties of the two forms of malic dehydrogenase from beef heart. J. Biol. Chem., 236: 1980, 1961.

\title{
Discussion
}

Dr. Yasuda :

1) The keratogenous zone often shows non-specific staining through the tetrazolium reduction. How was it in your present studies?

2) The crust of epidermal sweat duct which contain much sticky substance easily results in nonspecific staining by various histochemical reactions. How was your present observation?

3) How were the activities in myoepithelium of the sweat glands ?

Dr. Hashimoto :

1) Of hair cortex, the keratogenous zone may causes the nonspecific formazan deposition, but not of hair cuticle.

2) The epidermal sweat ducts show only specific reactions to some TPN-linked dehydrogenases.

\section{Histochemical Studies on the Damaged Liver}

\author{
Shigetoshi Ohkawa, Yoshiaki Okuda, Akima Mryoshi \\ and Gyoichi Wakisaka. \\ The First Division, Department of Internal Medicine, \\ Faculty of Medicine, Kyoto University.
}

Histochemical studies of the enzymes in the damaged liver have been successively performed by Wachstein et al. (1958) ${ }^{12}$. On the other hand, heterogeneity of enzymic activity within the liver lobule was pointed out histochemically by Novikoff $(1959)^{2)}$ and microchemically by Shank et al. (1957) ${ }^{3)}$.

In the present study liver injury was induced in animals and the histochemical findings of the liver at the various stages of the injury were successively investigated.

\section{Materials and Methods}

Acute intoxication of the liver was induced with $\mathrm{CCl}_{4}$ in rabbits and $\mathrm{DL}-$ ethionine in rats. In addition, partial hepatectomy was made in rats, according to the method of Higgins \& Anderson $(1931)^{4)}$. The animals were sacrificed by exsanguination and small blocks of the liver were promptly freezed by dry-ice. These blocks were cut in 15 microns in thickness by cryostat at $-18^{\circ} \sim$ $-15^{\circ} \mathrm{C}$ and the following enzymes were stained. 
1) Succinic dehydrogenase (Su. D.) : Rutenburg, Wolman, and Seligman $(1957)^{\text {s) }}$ (using Nitro-BT).

2) Glucose-6-phosphate dehydrogenase (G-6-PD) : Hess, Scarpelli and Pearse $(1958)^{6}$.

3) Diphosphopyridine nucleotide diaphorase (DPN-diaphorase): Nachlas, Walker and Seligman (1958) ${ }^{7}$.

4) Glucose-6-phosphatase (G-6-Pase) : Wachstein and Meisel (1956) ${ }^{8}$.

5) Adenosine Triphosphatase (ATP ase): Wachstein and Meisel (1958) ${ }^{\text {p) }}$

6) Alkaline phosphatase (Alk. Ph) Gomori's Cobalt Method (1952) ${ }^{10}$.

7) Acid phosphatase (Ac. Ph.) : Gomori (1950) ${ }^{11}$.

8) Lipase : Gomori (using Tween 60). (1952) ${ }^{12}$.

In addition, hematoxylin-eosin staining, Daddi's Sudan III fat staining, DNA, RNA, and PAS staining were made. Phase contrast microscopic observation was also performed to investigate the changes in the intracellular structures.

\section{Results}

In the normal liver, localizations of the enzymes studied within the lobules were different from enzyme to enzyme. DPN-diaphorase and G-6-Pase showed uniform reaction throughout the lobules. Whereas, the enzymic activities of G-6-PD, Su. D., Alk. Ph., AC. Ph. and ATP ase were much more intense in the perilobular area and that of lipase was remarkable in the centrolobular area.

1) Aute $\mathrm{CCl}_{4}$ intoxication.

The enzymic activities of Su. D., G-6-PD and DPN-diaphorase within the lobules were decreased 6 hours after $\mathrm{CCl}_{4}$ administration. However, intracellular distribution of the enzymes was not uniform, i. e., the enzymes were found to be remarkable in the perinuclear region and decreased to the periphery of the cells (Fig. 1). After 24 to 48 hours, the centrolobular area, where marked necrosis and hydropic degeneration were seen, showed no activity of these enzymes (Fig. 3). However, activities of the enzymes were much intense in the region adjacent to the necrosis 5 days after the administration, and enzymic activity within the lobules was more increased 10 days after the administration than that in normals (Fig. 4).

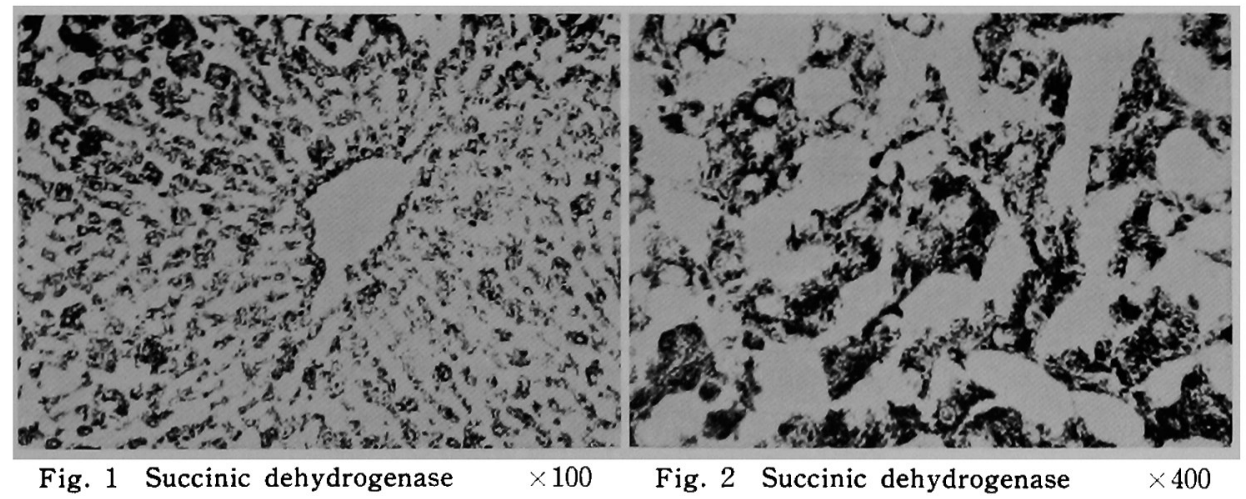

Six hours after $\mathrm{CCl}_{4}$ administration 


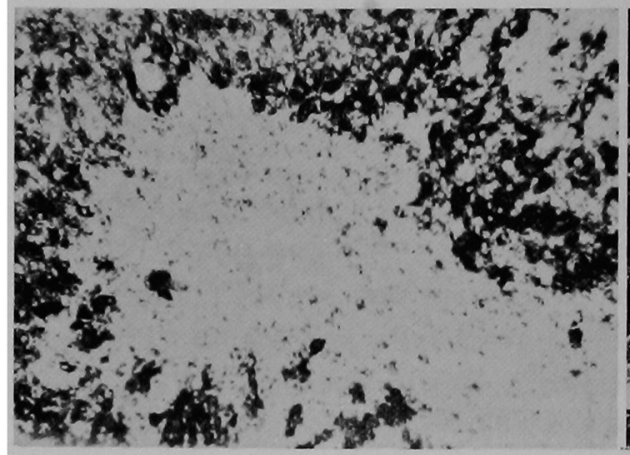

Fig. 3 Succinic dehydrogenase Two days after $\mathrm{CCl}_{4}$ administration

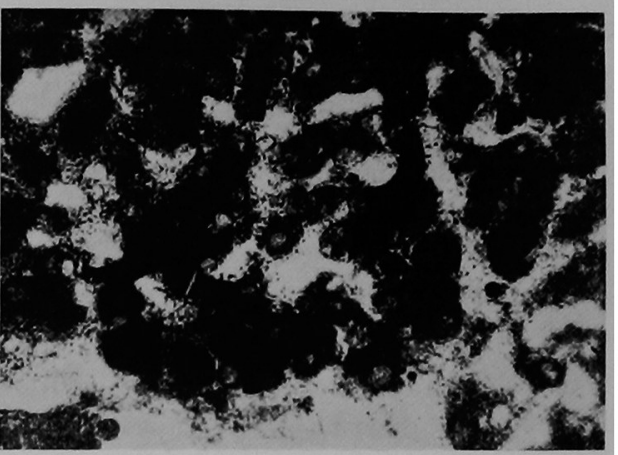

Fig. 4 Succinic dehydrogenase $\times 400$

These dehydrogenases were recovered to show normal intensity and distribution 2 weeks after $\mathrm{CCl}_{4}$ administration. On the contrary, after 24 to 48 hours, the activities of ATP ase, G-6-Pase and Alk. Ph. became completely negative in the necrotic region and was recovered to normal within 2 weeks.

On the other hand, the necrotic region and Kupffer cells surrounding it had remarkable activity of Ac. Ph. (Fig. 5). These changes were shown in Table 1.

2) Acute DL-ethioine intoxication

Fatty infiltration appeared within 24 hours after ethionine administration

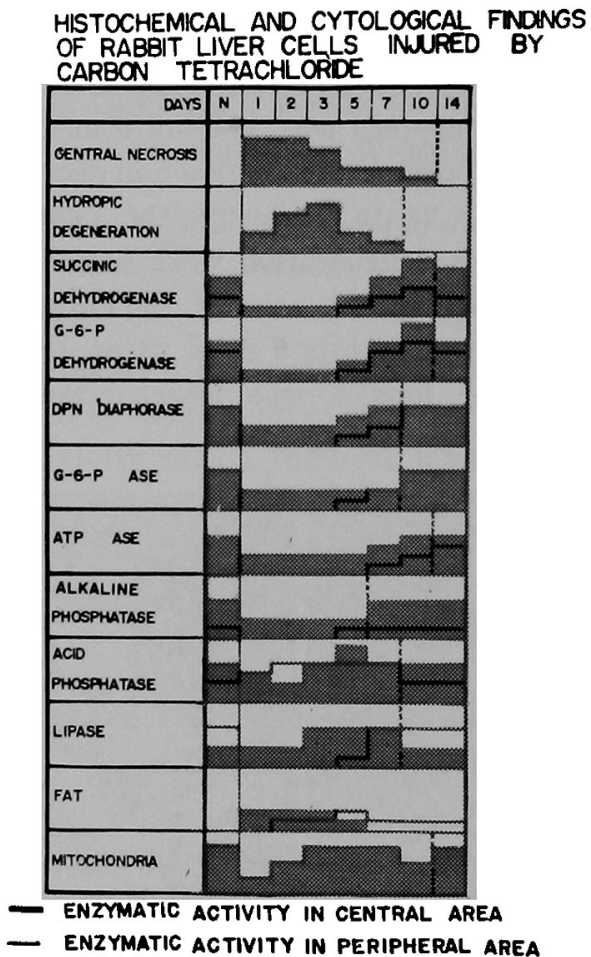

Table. 1 


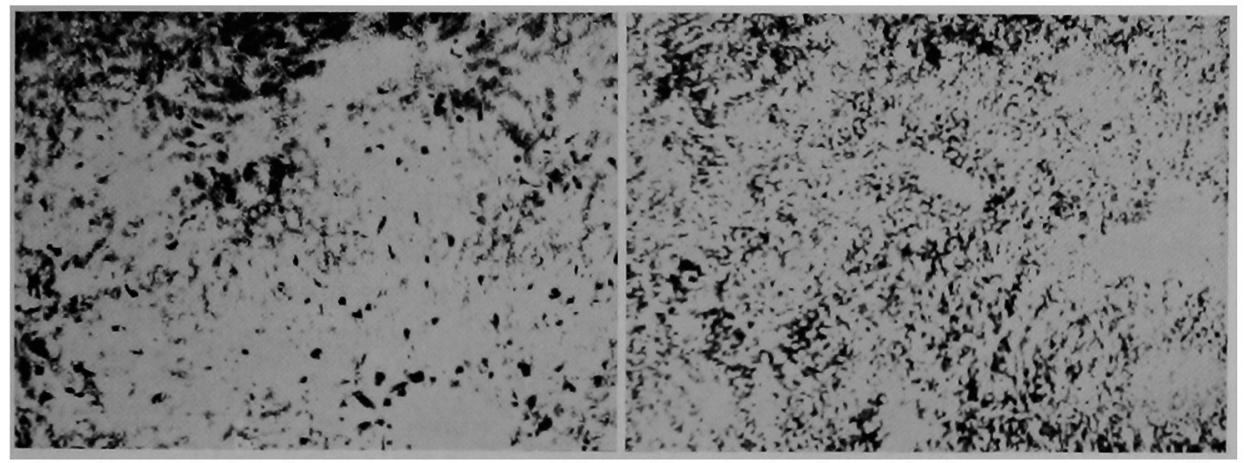

Fig. 5 Acid phosphatase $\times 100$

Fig. 6 Succinic dehydrogeuase

$\times 100$ Two days after $\mathrm{CCL}_{4}$ administration Two days after ethionine administration

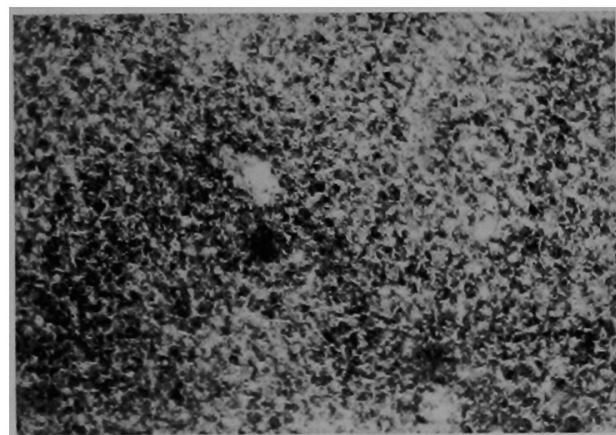

Fig. 7 G-6-P dehydrogenase $\times 100$ Two days after ethionine administration

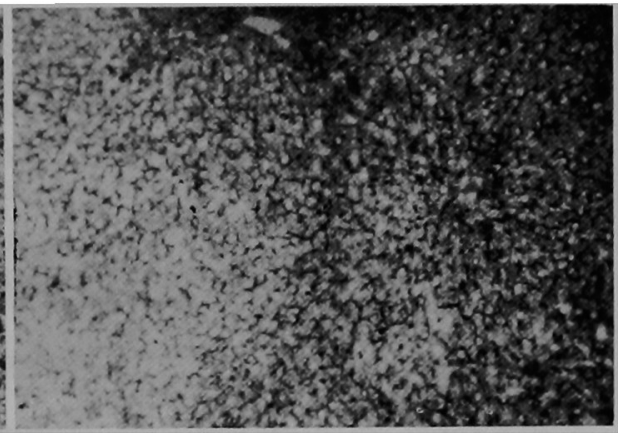

Fig. 8 ATPase

$\times 100$

Two days after ethionine administration

HISTOCHEMICAL AND CYTOLOGICAL FINDINGS OF RAT LIVER CELLS INJURED BY DL-ETHIONINE

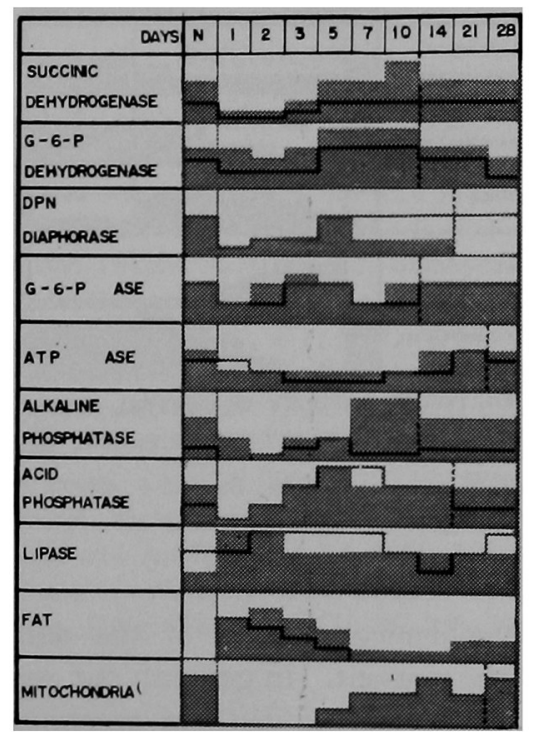

- enzYMATIC activity IN CENTRAL aREa

- ENzYMATIC ACTIVITY IN PERIPHERAL AREA

Table. 2 
and became maximum after 48 hours, when almost all kinds of enzymes are said to weaken their activities (Fig. 6.7.8). After 5 days, the enzymic activities were returned to normal, and after 10 days, were rather increased, especially in the perilobular area. After 10 to 14 days all the enzymic activities were recovered to normal. Recovery of the enzymic activities in the liver damaged with ethionine was shown in Table 2.

\section{3) Partial Hepatectomy}

Twenty-four hours after the partial hepatectomy, the formazan granules became larger in size, although they didn't disappear. After 48 hours, the enzymic activities were decreased when remarkable fatty infiltration was found. Aftter 3 weeks, the enzymic activities were more increased than those in normals, and formazan became coarse and were increased in number in the perilobular areas. After 4 weeks, these changes were recovered to normal.

These results were demonstrated in Table 3 .

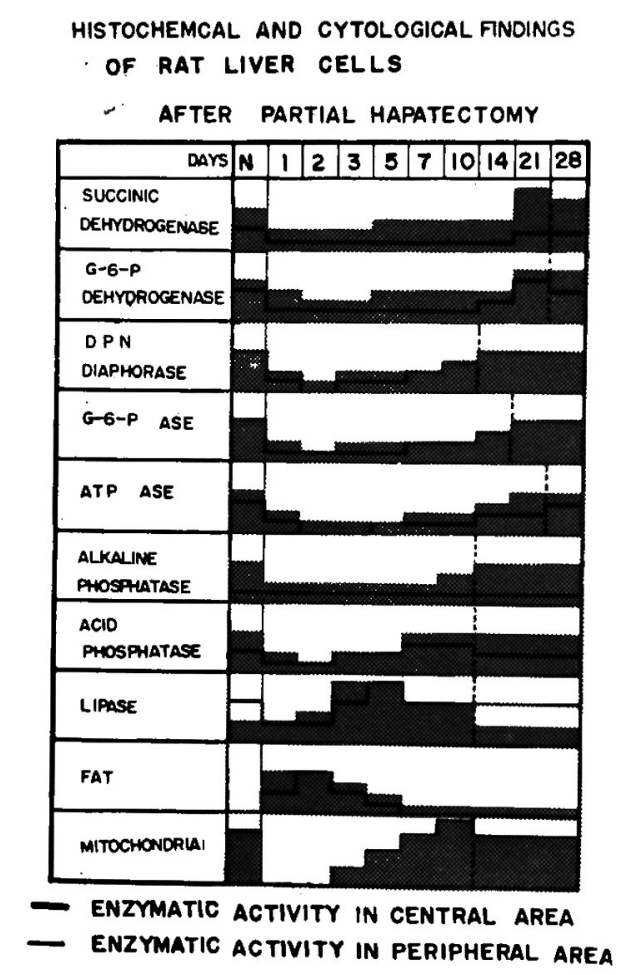

Table. 3

\section{Discussion}

Treatises on the histochemical studies of the damaged liver have been variously reported up to the present. In general, our results are similar to the results of their reports. However, the authors recognized that the activities of the dehydrogenases were increased temporarily before the recovery. On the other hand, the activities of Ac. Ph., Alk. Ph., ATP ase, G-6-Pase and Lipase 
were not so increased during this period.

This finding suggests that metabolism of the damaged liver cells is accelerated in the course of recovery, i. e., it is considered that the cell divisions are active and cytoplasmic volume and Krebs' cycle activity are increased during this period.

Stowell et al. (1953) ${ }^{18}$ had reported that the cytoplasmic volume reached at the maximum 2 to 3 weeks after partial hepatectomy and Pearse (1961) ${ }^{14}$ stated that succinate and malate dehydrogenase were thus the best indicators of Krebs' cycle activity from the histochemical point of view.

In both $\mathrm{CCl}_{4}$ and DL-ethionine poisoning, it is suggested that the identical situation occurs from 10 to 20 days after liver injury.

Hogeboom et al. $(1952)^{15)}$ had reported that cytochrome oxidase, succinic dehydrogenase and cyclophorase system exist in the mitochondria. In addition, there is a paper which states that either increase or decrease of mitochondria is related with the change of cytoplasmic volume ${ }^{16)}$. During this period, therfore, the activities of the dehydrogenases are increased temporarily more than those in normals.

\section{Summary}

The histochemical findings of the liver at various stages of injury were successively investigated.

The enzymic activities of the damaged liver are shown in Table 1.2.3. In acute $\mathrm{CCl}_{4}$ intoxication in rabbits, DL-ethionine intoxication in rats and partial hepatectomy in rats, the activities of the dehydrogenases were increased temporarily before the recovery. It is suggested that metabolism of the damaged liver cells is accelerated in the course of recovery.

\section{References}

1) Wachstein, M., and Meisel E : Arch. Path. $65: 449 ., 1958 . \quad 2)$ Novikoff, A. B.: J. Histchem. \& Cytochem. $7: 240,1959$. 3) Shank, R. E., et al. : J. Histchem. \& Cytochem. $7: 237,1957.4$ 4) Higgins, G. M., and Anderson, R. M., : Arch. Path., $12: 186,1931 . \quad 5)$ Rutenburg, A. M., Wolman, M., and Seligman, A. M., : J. Hist. \& Cytochem., $1: 66,1953$. 6) Hess, R., Scarpeli, D. G. and Pearse, A. G. E. : J. Biophyc. Biohem. Cytol. $4: 6.1958$. 7) Nachlas, M. M., Walker, D. G., and Seligman, A. M., : J. Biophys. Biochem. Cytol., $4: 29,1958 . \quad 8)$ Wachstein. M., and Meisel, E., : J. Histchem. \& Cytochem. $4: 592,1956$. 9) Wachstein, M, and Meisel. E., : Arch. Path. $65: 499,1958 . \quad 10$ ) Gomori, G., : Microscopic Histochemistry, Principles and Practice. Univ. Chicago Press. Chicago 1952 . 11) Gomori, G., Stain Technol. $25: 81,1950.12)$ Gomori, G., : Microscopic Histochemistry, Principles and practice. Univ. Chicago Press, Chicago 1952. 13) Wilson, M.E., Stowell, R.E., Yokoyama, H. O., and Tsuboi, K. K., Cancer Research. 13:86, 1953 . 14) Pearse, A. G. E. : Histochemistry, Theoretical and Applied. 2nd Ed, 1961. J. \& A. Churchill, Ltd., P. 574.

15) Hogeboom, G. H. and Schneider, W. C. : J. Biol. Chem., $194: 513,1952 . \quad 16)$ Takagi,

S. : Mem. Coll. Sci., Kyoto Imp. Univ., Series B. 15 : 167-206, 1939. 